\title{
TEXTO LITERÁRIO COMO INSTRUMENTO DA EDUCAÇÃO AMBIENTAL
}

José Ribamar Neres Costa ${ }^{1}$

Gilberto Luiz Alves²

Resumo: Este trabalho tem como objetivo investigar como os textos literários, em variados gêneros, podem servir como instrumento pedagógico de sensibilização ambiental, podendo despertar o interesse de leitores para problemas ambientais que, embora nem sempre façam parte do corpus central da obra literária, são ressaltados pelos autores e podem dar margens para discussões acerca de questões que envolvam o ambiente. $O$ estudo traz como objetos de análise textos escritos em três gêneros: poesia, literatura infantil e crônica, que são estudados sob as perspectivas da Educação Ambiental e da literatura, chegando-se à conclusão de que é possível a utilização de textos literário como instrumento de sensibilização para problemas ambientais.

Palavras-chave: Ambiente; Literatura; Sensibilização Ambiental; Educação Ambiental.

Abstract: This work aims to investigate how literary texts, in various genres, can serve as a pedagogical instrument for environmental awareness, and can arouse the interest of readers for environmental problems that, although not always part of the central corpus of the literary work, are highlighted by authors and can give scope for discussions about issues involving the environment. The study brings as objects of analysis texts written in three genres: poetry, children's and chronic literature, which are studied from the perspective of Environmental Education and literature, reaching the conclusion that it is possible to use literary texts as an instrument of awareness of environmental problems.

Keywords: Environment; Literature; Environmental Awareness; Environmental Education.

\footnotetext{
${ }^{1}$ Faculdade Pitágoras do Maranhão/Uniderp. E-mail: joseneres@globo.com.

Link para o Lattes: http://lattes.cnpq.br/5443711538608823.

2 Uniderp. E-mail: gilbertoalves9@uol.com.br.

Link para o Lattes: http://lattes.cnpq.br/0346629830466627.
}

Revbea, São Paulo, V. 15, № 7: 33-45, 2020.

revista brasileira 


\section{Introdução}

Há diversas formas de tentar sensibilizar as pessoas para a importância da preservação do ambiente ${ }^{3}$ e despertar o interesse pelo bem-estar coletivo tanto no momento atual quanto para as gerações futuras. Fotografias, documentários, estudos de casos, artigos científicos, reportagens, eventos, passeios e relatos são alguns dos recursos e estratégias que comumente são utilizados para alcançar tal intento. Contudo, um dos recursos que nem sempre é explorado com essa finalidade é o texto de caráter literário, que oferece múltiplas possibilidades de exploração dentro e fora de sala de aula.

À primeira vista, pode parecer que não exista uma relação direta entre leitura de textos literários e o processo de sensibilização de pessoas com relação à defesa, preservação e/ou conservação do ambiente. Contudo, os livros didáticos ou paradidáticos, atualmente, conforme indica Cademartori (2010, p. 17) "refletem acentuada consideração por temas sociais, como as diferenças raciais, sexuais, de classe, de habilidades e outras".

Sendo assim um desses temas que aparecem, tanto de forma periférica quanto de modo central em textos literários, é a relação do homem com o ambiente. E essa temática pode ser explorada tanto nas escolas quanto em outros ambientes educacionais por docentes de diversas disciplinas, como Biologia, Geografia, História, Sociologia, Química, Matemática, Artes e Língua Portuguesa, entre outras, dado o caráter transversal e multidisciplinar dos estudos ambientais.

Este trabalho foi realizado a partir de fontes secundárias como livros científicos e obras literárias de diversos autores, sem preocupação com corrente literária ou estilo de época, tendo como condição básica para que as obras literárias façam parte do corpus de estudo o fato de servirem para, a partir de sua leitura, despertar o senso crítico com relação aos problemas ambientais. Trata-se de uma pesquisa exploratória, que, segundo Rodrigues (2006, p. 90), "é realizada para descrever fenômenos ou estabelecer relações entre variáveis".

O artigo está dividido em duas partes complementares entre si. No primeiro momento, é feito um breve estudo sobre os três elementos de sustentação do trabalho, a saber: literatura (com ênfase no que é um texto literário), sensibilização e ambiente. Tais conceitos são amparados com base em teorias de autores como Brasil (1979), Moisés (1991), Proença Filho (1992), Bender e Laurito (1993), Pound (1997), Coelho (2000), Cademartori (2000) e Eagleton (2001). As questões ambientais e de sensibilização são estudadas pelo prisma do olhar de Moraes e Torre (2004), Berté (2013), Silva e Przybysz (2014) e Aroucha Filho (2018).

3 Embora seja corrente e até mesmo oficializada em texto jurídicos a nomenclatura meio ambiente, neste estudo os autores optaram pela utilização apenas da forma simplificada ambiente como referência ao meio ambiente. 
A seguir, são analisados textos literários em três gêneros específicos: literatura infantil, poesia e crônica, localizando neles elementos que comprovem a possibilidade de sensibilizar os leitores para problemas ambientais como descarte de resíduos, poluição, extinção de animais silvestres e desertificação, entre outros. Nesse tópico, fragmentos de obras literárias são cotejados com textos teóricos com a finalidade de comprovar a possibilidade de uso de textos artísticos para levantar discussões acerca de temas reais e sensibilizar os educandos dos mais diversos níveis e modalidades de ensino sobre os temas supracitados.

A relevância social do presente estudo aparece tanto na pertinência da discussão ambiental, que permeia todas as esferas da sociedade quanto na tentativa de apresentar sugestões de textos que podem ser trabalhados dentro e fora de sala de aula com o intuito de despertar o interesse tanto pela leitura em geral quanto por problemas relativos ao ambiente.

Para evitar possível redundância, neste estudo, houve preferência pela forma ambiente no lugar de meio ambiente, como é mais comum encontrar tanto nas falas cotidianas quanto em estudos de caráter técnico e científico.

\section{Texto Literário, Sensibilização e Ambiente}

Considerada como "uma forma de linguagem que tem uma língua como suporte" (PROENÇA FILHO, 1992, p. 29), a literatura nem sempre é vista como algo que possa ter uma finalidade imediata ou mesmo pragmática. Eagleton (2001, p. 10) chega a afirmar que "a literatura é um discurso 'não pragmático'; ao contrário dos manuais de biologia e recados deixados para o leiteiro, ela não tem nenhuma finalidade prática imediata, referindo-se apenas a um estado imediato das coisas". No entanto, apesar dessa aparência de não pragmatismo ${ }^{4}$, o texto literário, que "veicula uma forma específica de comunicação que evidencia um uso especial do discurso colocado a serviço da criação artística reveladora" (PROENÇA FILHO, 1992, p. 28), pode servir como ponto de partida ou mesmo suporte para discussões sobre infinitas temáticas que vão desde os pensamentos filosóficos até as necessidades mais prementes do ser humano nas mais diversas fases da história da humanidade.

Desse modo, os textos literários podem também ser utilizados, tanto na educação formal quanto na informal, como recurso didático-pedagógico para ajudar no processo de sensibilização das pessoas com relação à necessidade de cuidar do ambiente, a fim de que as gerações futuras possam ter acesso a recursos naturais que nem sempre são renováveis.

\footnotetext{
${ }^{4}$ Neste contexto, a palavra pragmatismo é utilizada no sentido exposto pela professora Nelly Novaes Coelho em vários de seus estudos, quando dividia as funções da leitura e da leitura como lúdica (com finalidade de entretenimento), pragmática (quando serve como base para estudos em diversos níveis) e catártica (quando desperta emoções nos leitores).
}

revista brasileira educação ambiental 
Sensibilizar, no sentido aqui empregado, embora tenha relação direta com a etimologia da palavra, vai além dos sentidos preconizados pelos verbetes dicionarizados de "tornar sensível; causar abalo; comover; abrandar o coração" (BUENO, 1992, 1042), atingindo uma dimensão política e pedagógica que remete à ideia de tentar fazer o leitor e demais envolvidos no processo reconhecerem:

a natureza como sendo algo vivo, que interage com o ser humano, como um sistema que entra em relação com os nossos sistemas biológico, psicológico, social e cultural e possibilita o nosso desenvolvimento como pessoa (MORAES e TORRE, 2004, p. 125).

Esse processo de sensibilização a partir do contato com textos literários em seus mais diversos gêneros busca também fazer o leitor refletir, sem precisar entrar em detalhes teóricos, sobre uma visão integradora, na qual tudo deve ser visto como "parte de um processo e o homem é visto como integrante do meio onde habita, e não como dono dele" (SILVA; PRZYBYSZ, 2014, p. 25), levando o ser humano a "rever e repensar seus gastos, hábitos de consumo e descarte adequado dos resíduos orgânicos e inorgânicos" (AROUCHA FILHO, 2018, 114).

Partindo do pressuposto de que "a arte é um dos meios do qual se vale o homem para conhecer a realidade" (PROENÇA FILHO, 1992, p. 14) e de que a literatura leva o homem a "vivenciar a experiência de maneira mais íntima, mais intensa" (EAGLETON, 2001, p. 5), é possível deduzir os possíveis efeitos de uma obra literária na percepção de quem tenha a oportunidade de ler/ouvir/sentir obras que discutam, com maior ou menor ênfase, temas como contaminação dos solos, da atmosfera e das águas, incêndios florestais e queimadas intencionais, degradação ambiental por meio do descarte irregular de resíduos, desertificação, catástrofes ambientais e mau uso dos recursos, como comentam Moraes e Torre (2001); gestão ambiental, políticas públicas em defesa do ambiente, gestão de recursos hídricos, crimes ambientais e gestão de resíduos (SILVA; PRZYBYSZ, 2014); impactos ambientais, ecologia e ambiente, instrumentos de proteção ambiental e degradação ambiental (BERTÉ, 2013) ou importância da preservação da fauna, da flora, dos rios, sustentabilidade ambiental, aquecimento global e uso dos agrotóxicos (AROUCHA FILHO, 2018).

Literatura infantil, poemas, contos, romances, crônicas, peças teatrais e outras variedades de textos às vezes trazem em seu bojo elementos temáticos relativos às questões ambientais e isso pode ser explorado de diversas formas dentro do processo de leitura e de interpretação de textos. Importante lembrar que, como ensinam Moraes e Torre (2004, p, 140), "o conhecimento científico não é a única forma de se referir a temas como meio ambiente", conforme será visto nos tópicos a seguir. 


\section{Literatura Infantil e Ambiente}

Os textos e livros voltados para o público infantil estão situados, como teoriza Cademartori (2010), em uma bifurcação entre o sistema literário e o sistema educacional, já que esse tipo de produção artística é utilizado principalmente como recurso didático pedagógico para desenvolver o gosto e as habilidades de leitura em alunos, principalmente nos primeiros momentos da vida escolar. Esse viés literário ainda é tão recente no mundo editorial que, como informa Coelho (2000) e Costa (2013), ainda não conta nem mesmo com um aparato crítico específico para análise e mensuração dos textos.

Apesar de utilizarem primordialmente a palavra como forma de expressão, o livro infantil acaba tornando-se uma mescla de múltiplas linguagens imbuídas no desejo de tentar fundir o prazer da leitura com a necessidade de aquisição de novos conhecimentos e a imersão no lúdico. Dessa forma, o livro desenvolvido para o público infantil acabou tornando-se:

Um ser-de-linguagem que se constrói como espaço de convergência de multilinguagens: narrativas em prosa ou poesia que se desenvolvem através de palavra, desenhos, pinturas, modelagem, fotografia, cerâmica, processos digitais ou virtuais, etc., etc. Linha de "criação complexa" que visa dar forma ou concretude a novas maneiras de ver e construir o real e, por isso, se empenha em provocar nos leitores o "olhar de descoberta" que a paisagem caleidoscópica do mundo atual exige, para que se possa interagir com ela (COELHO, 2000, p. 127).

Dessa forma, a literatura infantil, por conta de seus objetivos e de suas intersecções interdisciplinares, pode ser um terreno bastante fértil para inserir alguns preceitos da relação do homem com o ambiente. E é isso o que acontece no livro Os guardiães mirins, de Geane Lima Fiddan, que, em uma mescla entre teatro e prosa, utiliza-se de um inusitado encontro entre um garoto da cidade e uma sereia. Durante os diálogos, a protagonista aproveita para pedir que os seres humanos parem de jogar lixo nas águas do mar, pois essa ação está poluindo o ambiente marinho e matando os peixes e demais habitantes do mar. Conforme pode ser visto nos fragmentos a seguir:

FABRIZIO - Ei, eu vi na televisão que encontraram uma baleia na praia e ela estava cheia de coisas de metais. Tinha até um celular velho dentro dela. Será que foi isso que matou a bichinha?

[...]

PEQUENA SEREIA - Se você me ajudar, estará ajudando meu povo, que estará ajudando o seu povo! Tire as garrafas, os copos, os restos de coisas de malhas, metais e tudo de plástico e vidro e não sei mais o que, que estão sujando a nossa casa e nos adoecendo (FIDDAN, 2019, p. 12-13). 
A leitura do livro e a posterior discussão de seu conteúdo e de suas temáticas podem despertar nos jovens leitores o interesse pela preservação das águas e estimular atitudes e campanhas para minimizar os efeitos da poluição, pois é sabido que "uma grande quantidade desses resíduos está sendo despejada na superfície e no fundo de mares e rios, causando grandes problemas à fauna aquática" (AROUCHA FILHO, 2018, p. 16). Textos literários que chamem a atenção para o assunto da poluição podem levar o educando, e consequentemente as pessoas de seu entorno, a uma tomada de consciência ambiental e a uma possível mudança de paradigma e estimulando "uma prática de gestão participativa" (BERTÉ, 2013, p. 69), já que atitudes desse tipo não devem ficar na dependência exclusiva de políticas públicas.

O descarte irregular de resíduos sólidos no ambiente aquático é também o tema motivador do livro Marcelinho e seus porquês em sua primeira visita à praia, de Jorge Luiz Silva Nunes, que aproveita o passeio de uma família para apresentar o mar a "um garotinho de 5 anos que, apesar de sua pouca idade, é bastante observador, muito curioso, inteligente e sempre atento a tudo o que acontece a seu redor" (NUNES, 2016, p. 6). Ao longo da narrativa, o menino vai questionando o pai sobre a importância, as características, a flora e a fauna marinha, com ênfase na degradação do espaço e na poluição visível aos olhos dos frequentadores do local. Em uma visão sistêmica, onde todos os elementos estão de alguma forma interligados, o autor acaba chamando a atenção também para o consumismo desenfreado, que "provoca não apenas a escassez de recursos naturais, mas também a geração de milhões de toneladas de resíduos" (SILVA; PRZYBYSZ, 2014, p. 21), conforme pode ser visto no fragmento abaixo:

Marcelinho, o mar poderia ser mais bonito ainda, pois a poluição marinha e a exploração de vários recursos têm causado a morte de vários organismos. Alguns chegando à beira da extinção. $\mathrm{O}$ homem não é o único ser que polui o ambiente, mas é aquele que realmente faz a diferença. As principais fontes poluidoras do ambiente marinho são as cidades, indústrias e navios. As maiores cidades do país e do mundo estão situadas próximas às praias, contribuindo bastante para a degradação ambiental. As indústrias não tratam seus resíduos, que, na sua grande maioria, são venenosos, e os lançam diretamente no mar. $E$ os navios estes sempre são manchetes de jornais em casos de derramamento de petróleo que provocam repercussão mundial. Imagine no ambiente marinho! (NUNES, 2016, p. 13-14).

Depois de conhecer diversos habitantes da fauna marinha, de entrar em contato com as belezas e com os perigos do mar, Marcelinho sente vontade de levar uma concha para casa, como lembrança de seu primeiro contato físico com o mar, mas é dissuadido pelo pai, que alerta para os perigos da retirada de elementos da natureza de seu espaço original e suas possíveis consequências. 
Agora imagine se todas as pessoas pensassem dessa maneira? Nós nunca veríamos uma concha sequer na areia, ou então nunca haveria reciclarem no ambiente. foi muito bom ter acontecido isso, pois acabei me lembrando do lema dos excursionistas: 'Na natureza, a única coisa que deixamos são as pegadas e as únicas coisas que trazemos conosco são belas fotos e boas lembranças' (NUNES, 2016, p. 25-27).

Como, de forma geral, a criança "não se interessa por livros que não the trazem nada de novo, não the surpreendem com algo que ela ainda não pensou" (CADEMARTORI, 2010, p. 35), a literatura infantil, ou mesmo a infanto-juvenil, pode ser utilizada como recurso didático-pedagógico para despertar nos leitores o senso de que é preciso cuidar da natureza e do ambiente hoje para que as gerações vindouras tenham acesso aos recursos necessários à manutenção da vida humana de modo equilibrado, conforme evidenciam, em seus trabalhos, Silva e Przybysz (2014), Berté (2013) e Aroucha Filho (2018).

\section{Poesia e Ambiente}

A poesia, conceituada por Pound (1997, p. 40) como "a mais condensada forma de expressão verbal', por Moisés (1991, p. 40) como a "expressão do 'eu' por meio de metáforas" e por Ernest Fraeri (apud BRASIL, 1979 , p. 169) como "atividade imediata da natureza criativa do homem, que plasma incessantemente o próprio mundo", oferece diversas oportunidades de interpretação tanto da realidade interna quanto externa do indivíduo, podendo servir para diversos fins, que vão desde o questionamento emocional e/ou filosófico até a denúncia social, passando também pela possiblidade de despertar os leitores para os problemas ambientais que fazem parte do cotidiano, mas para os quais nem sempre as pessoas estão atentas.

Um exemplo disso é o poema abaixo, escrito pelo poeta Alex Brasil5, no qual, seguindo os conselho de Ezra Pound, aparece, de modo sintético um pouco da história de uma lagoa, situada no Sítio Santa Eulália, parte de uma reserva florestal situada em São Luís do Maranhão (2³0'38"S / 4416'37"W), mas que, na década de 90 do século $\mathrm{XX}$, acabou sendo vítima de uma tentativa de exploração imobiliária e teve parte de seu patrimônio natural devastado, inclusive com o desaparecimento da lagoa de que trata o poema.

${ }^{5}$ Alex Brasil é o nome literário do jornalista, publicitário, contista e poeta Alsenor Duailibe Garcia, ocupante da cadeira 30 da Academia Maranhense de Letras. 
Lagoa Santa Eulália

No Santa Eulália havia uma Lagoa Verde, coroada de buritizal.

Até que a humana fera, com sede, engoliu a Lagoa Verde, e vomitou, no mesmo local, o progresso cinza e deserto, menos vida, porém mais racional: para que o verde, se o lucro é mais certo? (BRASIL, 1995, p. 95).

A atividade antrópica, no poema indicada metaforicamente pela expressão "humana fera" e pela indicação da busca de lucro no último verso, é vista como causa da mudança de paisagem, somada à substituição de palavras que remetem a elementos da natureza (lagoa, verde, buritizal) por palavras como "cinza e deserto" que remetem aos impactos ambientais causados pela ação humana e aos problemas decorrentes da falta de uma gestão ambiental voltada para a responsabilidade social, ou seja, para o "envolvimento de todas as pessoas e de todos os setores na gestão ambiental" (BERTÉ, 2013, p. 39).

Em um texto voltado para o público adulto, poeta piauiense $\mathrm{H}$. Dobal, depois de dizer que se considera traído pela própria espécie humana que acabou destruindo a natureza, traz em sua Lamentação ecológica, um sentimento de revolta sobre o atual estágio de algumas paisagens que faziam parte de sua memória afetiva. Diz o poeta:

[...] os rios revoltados, o poluído coração das águas.

A lua devassada

o luar desaparecido num tempo todo morto.

Um canto um chamado de pássaro.

A migração das marrecas

a maturação das mangas.

O tempo despercebido.

Essa dor renitente por tudo o que vai mudando

a lenta extinção das espécies nos Jardins Zoológicos.

O mar insatisfeito,

a luz envenenada,

a derrotada defesa do ozônio.

Estrelas turvas, terras tristes

onde se planta a vanguarda do deserto.

A chuva ácida, que não acorda os campos,

Até o amor

só lembranças

do que não existiu. 
Essa dor de tudo que o homem

e outras forças da natureza

vão destruindo

(DOBAL, 2002, p. 113).

Nesse poema fica claro que a relação do homem com a natureza é conflituosa e traz sempre algum tipo de impacto ambiental, que é conceituado pela Resolução Conama 01/ 1986 (apud BERTÉ, 2013, p. 121) como sendo:

(...) qualquer alteração das propriedades físicas, químicas e biológicas do meio ambiente causadas por qualquer forma de matéria ou energia resultante das atividades humanas que, direta ou indiretamente, afetam: I - a saúde, a segurança e o bem-estar da população; II - as atividades sociais e econômicas; III - a biota; IV - as condições estéticas e sanitárias do meio ambiente; $\mathrm{V}$ - a qualidade dos recursos ambientais.

Desta forma, de modo poético e lúdico, o eu lírico do poema acaba trazendo à baila temas como poluição, alterações climáticas, diminuição da camada de ozônio, migração de animais silvestres pelas condições adversas, desertificação, chuva ácida e outros problemas ambientais. No texto literário, o poeta mantém um diálogo intertextual com o que diz Aroucha Filho (2018, p. 25), quando afirma que "o homem é o principal causador desses danos ambientais, pois está destruindo nossos biomas sem ao menos conhecer nossa exuberante diversidade biológica".

A concepção recorrente de que a percepção capitalista do ser humano é a grande responsável pelo caos ambiental no qual a humanidade está inserida é também defendida pelo poeta paraibano José Chagas, que, após criticar a grilagem, a falta de reforma agrária, a exploração do homem e outras temáticas envolvendo a relação do homem com a terra, diz que:

A consciência de uma ecologia é só o homem que tem, o bicho não, mas tem o homem também a forma fria de raciocinar contra a razão, numa particular filosofia a insinuar que o louco é que é o são e que o homem destrói, com alegria, aquilo que lhe dá satisfação, como se a natureza, tão sadia, tudo quanto fizesse fosse em vão, e a terra não valesse a poesia que até os próprios animais nos dão, pois o homem quer vê-la tão vazia quanto já tem vazio o coração (CHAGAS, 2002, p. 109). 
Nesse poema, o ser humano e os demais seres são bem delimitados a partir de vocábulos antagônicos que os definem (homem $\mathrm{X}$ bicho/animais) e por uma marca própria que seria a consciência de seu fazer/estar no mundo. No entanto esse diferencial tende a desaparecer diante de ações que levam o homem a destruir, "com alegria, aquilo que lhe dá satisfação", ou seja, ele está consciente da destruição que causa à natureza e ao ambiente como um todo.

Como, de alguma forma, "ao estudarmos a história das culturas e o modo pelos quais elas foram transmitidas de geração para geração, verificamos que a Literatura foi o principal veículo para a transmissão de seus valores de base", conforme defende Coelho (2000, p. 13), essa mesma literatura em suas mais diversas formas e gêneros pode ser utilizada como instrumento didático em defesa da preservação ambiental e do uso equilibrado dos recursos oferecidos pela natureza.

\section{Crônica e Ambiente}

Crônica é um texto híbrido que oscila entre a linguagem jornalística e a literária que "nasce nas páginas dos jornais e só posteriormente é enfeixada em livro, procurando o seu autor dar-lhe um status mais perene, ou mais nobre" (BRASIL, 1979, p. 53), trazendo como uma das características principais a descrição de "acontecimentos do presente, da vida política, policial, literária, esportiva, explorando, ou o tom do humor, do sarcasmo ou de crítica social", conforme teoriza Brasil (1979, p. 53). Como "o cronista aproveita seu espaço para confidências, como se o leitor fosse um amigo" (BENDER; LAURITO, 1993, p. 77), tais textos podem servir também como pretexto para trabalhar, na educação formal ou na informal, elementos, estruturas e teorias que remetam às questões ambientais.

Nem sempre o fato de uma crônica, um conto, uma peça teatral, um poema ou qualquer outro texto literário fazer referência a elementos da natureza significa dizer que seja uma obra voltada para a defesa do ambiente, já que, às vezes, trata-se apenas de um recurso estético para compor a ambientação, sem necessidade explícita de desenvolver um discurso que demonstre interesse pelas causas ambientais. No entanto, existem casos em que há um amálgama entre o discurso em defesa do ambiente e a descrição da paisagem.

É o caso de $O$ congresso das garças, de Ivan Sarney. Ao longo das 60 crônicas que compõem o livro, o autor remete a diversos temas que podem levar o leitor a reflexões acerca da relação homem $x$ natureza. Em um estilo leve, com um vocabulário acessível, sem recorrer necessariamente a termos científicos e/ou técnico e em tom de quase conversa com o leitor, o cronista, como dizem Bender e Laurito (1993), utiliza-se do dia a dia e de elementos do cotidiano aparentemente banal como fonte de inspiração para seus textos.

Como tem liberdade de expressão, "o cronista faz o que quer, inclusive critica filme, teatro ou livro, sem ser crítico de arte" (BENDER; LAURITO, 1993, 
p. 77). Dentro dessa perspectiva, nada impede também o cronista de falar sobre o ambiente e da relação do homem com a natureza sem ter necessariamente formação acadêmica no assunto.

Ao longo do livro, vários textos remetem diretamente ao convívio do narrador com a natureza, sempre em uma atitude de contemplação e respeito, como ocorre na crônica intitulada Um pássaro contra a janela, que começa da seguinte forma:

Quase toda manhã, um passarinho alegre vem visitar nosso apartamento. Ele é um entre dezenas de pássaros que, todos os dias, anunciam a chegada das manhãs, na rua das Andirobas e suas adjacências (SARNEY, 2016, p. 47).

Em outra crônica, o escritor se dedica a comentar sobre a presença de camaleões durante suas caminhadas matinais. Embora a ideia geral do texto seja traçar um paralelo entre as características do camaleão e das pessoas, é possível detectar, na leitura integral do texto, alguns elementos que remetem à diversidade da fauna e da flora, à falta de conservação, ao uso recreativo do ambiente e à contemplação da natureza sem necessidade de modificá-la ou destruí-la ${ }^{6}$, conforme pode ser visto no parágrafo introdutório:

Há algum tempo, em nossas caminhadas matinais pela Lagoa da Jansen, venho observando na diversidade de vidas que ali se exibem e desenvolvem, alguns camaleões que costumam ficar sobre um muro mal cuidado que dá para um terreno baldio onde brotam nanas amarelas, em qualquer estação (SARNEY, 2016, p. 47).

Mesmo sem se preocupar com a nomenclatura técnica, torna-se visível a preocupação do autor com uma visão ecossistêmica do planeta, considerando o ambiente como "um conjunto único e indissociável" (BERTÉ, 2013, p. 28), pois:

Afinal, somos seres vivos, integrantes do sistema planetário onde a Terra se insere, e não poderia ser diferente conosco, pois fazemos parte da biodiversidade do nosso planeta, numa ordem universal (SARNEY, 2016, 156).

\footnotetext{
${ }^{6}$ Sabe-se que mesmo nos momentos de contemplação da natureza a intervenção antrópica é capaz de causar danos para o ambiente. Neste trecho, porém, não se levam em conta os impactos causados pela presença do elemento humano no processo de observação, mas sim a intencionalidade em prejudicar ou não o ambiente.
} 
Em uma concepção bastante próxima à de Ivan Sarney, o também cronista Luiz Carlos Amorim, em 2013, por ocasião das comemorações da Semana Mundial do Meio Ambiente publicou um texto no qual coloca o ser humano como responsável pela saúde do planeta.

Não cuidamos do lugar onde vivemos, fragilizamos a saúde do planeta, envenenamos o ar, a água, a terra, o mar. O resultado é a nossa saúde fragilizada. Precisamos devolver a saúde ao meio ambiente, ao planeta, para restabelecer a nossa própria saúde. Com muita urgência. Porque o tempo está se esvaindo. Há que se trabalhar, e muito, com muita urgência, pelo restabelecimento da saúde do planeta. Como poderemos nos redimir, se cometemos incomensuráveis crimes contra o meio ambiente, não cuidando direito da coisa mais elementar, do mais básico, que é o nosso lixo? É assim que cuidamos da natureza? (AMORIM, 2019).

No fragmento acima é possível perceber um diálogo teórico, ideológico e intertextual com Berté (2013), Silva e Przybysz (2014) e Aroucha Filho (2018) que também defendem, em seus trabalhos teóricos, a necessidade de mudança de paradigma para o bem do planeta e de todos os habitantes dele.

\section{Conclusão}

Um texto literário (conto, crônica, peça teatral, romance, poesia, etc.) pode ser lido e estudado sob diversas perspectivas, servindo tanto para as finalidades lúdicas quanto para objetivos pragmáticos, como, por exemplo, tentar inserir nos leitores elementos que os levem a um processo de sensibilização com relação aos problemas ambientais.

Durante a leitura de uma obra literária, é possível identificar diversas temáticas que podem aparecer ora como principais ora como subjacentes ao texto e perceber a presença a alguns dos principais problemas ambientais enfrentados pela sociedade, como poluição, descarte de resíduos, desertificação, mudanças climáticas e outros. Os textos podem então servir como pretexto para debater esses temas e tentar sensibilizar os receptores para assuntos que poderiam passar despercebidos em um contato apenas lúdico com as obras.

Ao longo deste artigo, foi visto que literatura infantil, poemas e crônicas, de diversos autores, podem ser utilizados como instrumento didático, pedagógico e até mesmo político para demonstrar que é possível fazer algo pelo bem-estar tanto da geração atual quanto das vindouras e que a literatura, assim como os estudos científicos, é um valioso recurso para mostrar que é preciso pensar em novos paradigmas na relação do homem com o ambiente. 


\section{Referências}

AMORIM, L.C. Meio ambiente e ecologia. Disponível em: $<$ http://luizcarlosamorim.blogspot.com/2013/06/meio-ambiente-e-

ecologia.html>. Acesso em 23.12.2019.

AROUCHA FILHO, J. C. Meio ambiente \& práticas sustentáveis. 2ª ed. Caxias: Academia Caxiense de Letras, 2018.

BENDER, F.; LAURITO, I. Crônica: história, teoria e prática. São Paulo: Scipione, 1993.

BERTÉ, R. Gestão socioambiental no Brasil: uma análise ecocêntrica. Curitiba: Intersaberes, 2013.

BRASIL, A. Ilha verde. São Luís: Gráfica Escolar, 1995.

BRASIL, A. Vocabulário técnico de literatura. Rio de Janeiro:Tecnoprint, 1979.

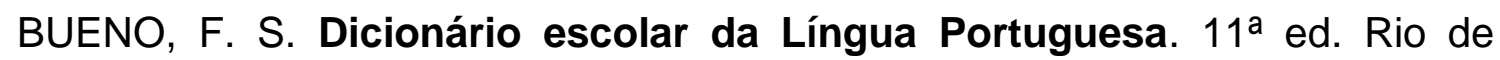
Janeiro: Ministério da Educação: 1992.

CADEMARTORI, L. 0 que é literatura infantil. $2^{\underline{a}}$ ed. São Paulo: Editora Brasiliense, 2010.

CHAGAS, J. De lavra e de palavra ou campoemas. São Luís: Sotaque Norte Editora, 2002.

COELHO, N. N. Literatura: arte, conhecimento e vida. São Paulo: Fundação Peirópolis, 2000.

COSTA, J. J. S. Era uma vez um lugar. São Luís: Ufma, 2013.

DOBAL, H. Gleba de ausentes: uma antologia provisória. Teresina, 2002.

EAGLETON, T. Teoria da literatura: uma introdução. $4^{\underline{a}}$ ed. São Paulo: Martins Fontes, 2001.

FIDDAN, G. L. Os guardiães mirins. São Luís: Editora Feliz, 2019.

MOISÉS, M. A análise literária. 9ee. São Paulo: Cultrix, 1991.

MORAES, M. C; TORRE, S. L. SentiPensar: fundamentos e estratégias para reencantar a educação. Petrópolis: Vozes, 2004.

NUNES, J. L. S. Marcelinho e sus porquês em sua primeira visita à praia. $2^{\text {a }}$ ed. São Luís: Café e Lápis/Edufma, 2016.

POUND, E. Abc da literatura. 12ª ed. São Paulo: Cultrix, 1997.

PROENÇA FILHO, D. A linguagem literária. 4ª ed. São Paulo: Ática, 1992.

RODRIGUES, A. J. Metodologia cientifica completa e essencial para a vida universitária. São Paulo: Avercamp, 2006.

SARNEY, I. O congresso das garças. São Luís: Academia Maranhense de Letras/Unigraf, 2016.

SILVA, C.; PRZYBYSZ, L. C. B. Sistema de gestão ambiental. Curitiba: Intersaberes, 2014. 